Chapter 6

\title{
Circulating Methylated DNA as Biomarkers for Cancer Detection
}

\author{
Hongchuan Jin, Yanning Ma, Qi Shen and \\ Xian Wang \\ Additional information is available at the end of the chapter \\ http://dx.doi.org/10.5772/51419
}

\section{Introduction}

In addition to genetic alterations including deletion or point mutations, epigenetic changes such as DNA methylation play an important role in silencing tumor suppressor genes during cancer development. By adding a methyl group from S-adenosyl-L-methionine to the cytosine pyrimidine or adenine purine ring, DNA methylation is important to maintain genome structure and regulate gene expression. In mammalian adult tissues, DNA methylation occurs in CpG dinucleotides that often cluster in the genome as CpG islands in the 5' regulatory regions of the genes. Through recruiting transcriptional co-repressors including methyl-CpG-binding domain proteins (MBDs) and chromatin remodeling proteins like histone deacetylases (HDACs) or impeding the binding of transcriptional activators, DNA methylation could suppress the transcription of many tumor suppressor genes critical to cancer initiation and progression [1-3].

More and more results confirmed that cancer is a multi-stage process fuelled by many epigenetic changes in addition to genetic changes in DNA sequence [4]. Chemical molecules like Trichostatin A (TSA) and 5-aza-2'-deoxycytidine (5-Aza-CdR) targeting epigenetic regulators such as histone modifications and DNMTs (DNA methyltransferases) have been found to inhibit tumor growth both in vitro and in vivo. By reversing the epigenetic silencing of important tumor suppressor genes, an increasing number of epigenetic drugs such as 5-AzaCdR, 5-Aza-CR and Vorinostat (SAHA) are currently investigated in the clinical trials for cancer treatment as a single drug or in combination with other epigenetic drugs or other approaches such as chemotherapy and showed very promising activities by offering significant clinical benefits to cancer patients [5-13]. 
As one of the major epigenetic changes to inactivate tumor suppressor genes critical to human cancer development, DNA methylation was recognized as the biomarker for cancer detection or outcome prediction in addition to the identification of novel tumor suppressor genes. DNA mutations will occur randomly in any nucleotides of one particular gene and the comprehensive determination of DNA mutations is thus very difficult and time-consuming. In contrast, aberrant DNA hypermethylation usually takes place in defined CpG Islands within the regulatory region of the genes and it is much more convenient to detect DNA methylation in a quantitatively manner. In addition, DNA methylation can be amplified and is thus easily detectable using PCR-based approaches even when the DNA concentration after sample extraction is relatively low. Due to such advantages over DNA mutation- or protein-based biomarkers, DNA methylation-based biomarkers have been intensively investigated in the recent years. A large body of research reports has proved the value of DNA methylations in the prognosis prediction and detection of various cancers. DNAs used for such methylation analyses are usually extracted from tumor tissues harvested after surgical operation or biopsy, thus limiting its wide application as the biomarkers for the early detection or screening of human cancers. Recently, it has been reported that there are certain amount of circulating DNAs in the peripheral blood of cancer patients, providing an ideal source to identify novel biomarkers for non-invasive detection of cancers. Both genetic and epigenetic changes found in the genomic DNAs extracted from primary tumor cells could be detected in the circulating DNAs, indicating that the detection of methylated DNAs in the circulation represents a new direction to develop novel biomarkers for cancer detection or screening in a non-invasive manner.

\section{Cell free DNA in the circulation}

According to the origin of circulating tumor-related DNA, it could be grouped into circulating cell free DNA or DNA from cells in the blood such as circulating tumor cells (CTC) in cancer patients (Figure 1).

In 1869, the Australian physician Thomas Ashworth observed CTCs in the blood of a cancer patient. Therefore, it was postulated that CTCs were responsible for the tumor metastases in distal sites and should have important prognostic and therapeutic implications [14-16]. However, the number of CTCs is very small compared with blood cells. Usually around 1-10 CTCs together with several million blood cells could be found in $1 \mathrm{ml}$ of whole blood, making the specific and sensitive detection of CTCs very difficult [17-18]. Until recently, technologies with the requisite sensitivity and reproducibility for CTC detection have been developed to precisely analyze its biological and clinical relevance. The US Food and Drug Administration (FDA) approved the test for determining CTC levels in patients with metastatic breast cancer in 2004. Currently, it has been expanded to other cancer types such as advanced colorectal cancer and prostate cancer. Although CTCs-counting based test have proven its value in predicting prognosis and monitoring therapeutic effects, the number of CTCs per ml of blood limited its sensitivity greatly [19]. With the development of high-sensitive PCR-based methods, the detection of gene mutations or epigenetic changes such as 
DNA methylation within small amount of CTCs could be the next generation of CTC-based test for cancer detection. However, the cost of such tests will be greatly exacerbated, thus limiting its wide application in the clinic [20-22].

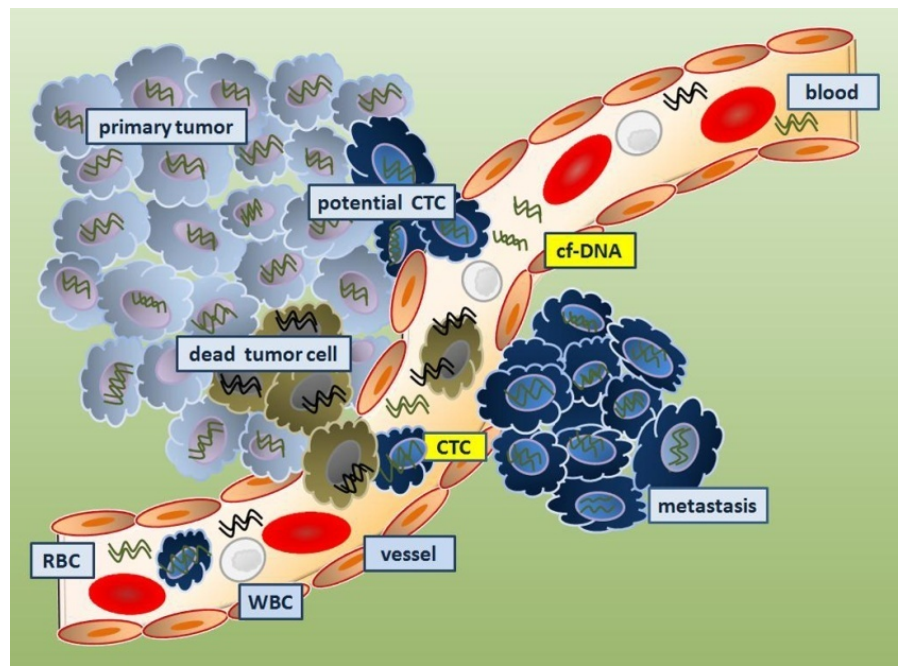

Figure 1. Circulating tumor cells and cell free DNA. Circulating Tumor cells (CTC) escape from primary sites and spread into the vessel to form metastases in the distal organs with. Cell free DNAs (cf-DNAs) are released into the circulation from dead cancer cells or proliferating tumor cells. RBC: red blood cell; WBC: white blood cell.

Although its origin and biological relevance remains unknown, circulating cell free DNA (cfDNA) is supposed to be valuable source to identify cancer markers with ideal sensitivity and specificity for non-invasive detection of cancer [23-24]. Early in 1948, two French scientists Mandel and Metais firstly reported the presence of cf-DNAs in human plasma [25]. Such an important discovery has been unnoticed for a long time until cell-free circulating nucleic acid was found to promote the spread and metastasis of crown gall tumor in plants [26]. Subsequently, increased level of cf-DNAs was found in patients with various diseases such as lupus erythematosus and rheumatoid arthritis cancer [27-28]. In 1977, Leon et al. reported that higher level of circulating DNA in the plasma of cancer patients when compared to healthy controls. Moreover, greater amounts of cf-DNA were found in the peripheral blood of cancer patients with tumor metastases and cf-DNA levels decreased dramatically after radiotherapy while persistently high or increasing DNA concentrations were associated with a lack of response to treatment [29], clearly revealing the potential value of cf-DNA as biomarker for cancer detection. Following studies confirmed that cf-DNAs in the plasma contains genetic and epigenetic changes specific to DNAs within the tumor cells from primary tissues, indicating that tumor specific cf-DNAs are originated from tumor cells rather than lymphocytes reacting towards the disease [30-31]. For example, K-Ras mutation was found in cf-DNA from 17 out of 21 patients with pancreatic adenocarcinoma and mutations were similar in corresponding plasma and tissues samples. Importantly, such DNA alterations were found in 
patients with pancreatitis who were diagnosed as pancreatic cancer 5-14 months later, indicating that release of tumor-specific DNA into the circulation is an early event in cancer development and cf-DNA could be used as the biomarkers for early cancer detection [32]. Treatment resulted in disappearance of K-Ras mutations in plasma DNA in six of nine patients. Three patients with a persistently positive K-Ras gene mutation in plasma samples from patients before and after treatment showed early recurrence or progression and pancreatic carcinoma patients with the mutant-type K-ras gene in plasma DNA exhibited a shorter survival time than patients with the wild-typegene, indicating the cf-DNA could beof valuein monitoring disease progression or evaluating treatment response [31,33].

Through quantitatively analyzing plasma DNAs from patients with organ transplantation, Lo et al found that the majority of plasma DNAs was released from the hematopoietic system. However, donor DNA could be detected in the plasma of recipients suffering from the graft rejection because of the large amount of cell death which promotes the release of donor DNAs into the peripheral blood of the recipients [34]. Therefore, it was postulated that cellfree tumor related DNA could originate from the apoptotic tumor cells since high-rate of apoptosis indeed occurs in primary and metastatic tumor tissues. However, cf-DNA quantities are significantly reduced in cancer patients after radiotherapy when a great number of tumor cells were believed to undergo apoptotic cell death and cf-DNAs in supernatants of cultured cancer cells increases with cell proliferation rather than apoptosis or necrosis, indicating that proliferating tumor cells could actively release cf-DNA into the tumor microenvironment and circulation.

In contrast to labile RNAs that were included into the actively secreted exosomes, the nature of cf-DNAs remains to be clarified. As negatively charged molecules, cf-DNA was bound by plasma proteins to escape from endonuclease-mediated degradation. Unfortunately, plasma proteins bound to cf-DNAs was not well characterized yet. Meanwhile, secreted exosomes could remodel microenviroments and promote tumor metastasis since RNAs within exosomes especially microRNA with high stability may influence gene expression in neighbor cells. The biological relevance of cf-DNAs remains unknown. DNA was believed to be more structural rather than functional. However, it was supposed that cf-DNA could play a role as vaccine in tumor microenvironment.

\section{Methods for the detection of methylated DNA}

It is unclear so far whether serum or plasma is better for cf-DNA extraction. Although the DNA amount is significantly higher in the serum, the majority of the increase was due to the release of nuclear acids from destroyed blood cells during blood clotting [35]. In addition, the time gap between blooding drawing and DNA extraction as well as the methodologies used for DNA isolation contribute greatly to the amount of cf-DNA harvested. On an average, around 30 ng cf-DNA could be extracted from one ml of blood sample [36]. Therefore, in order to determine the quantity of potential cf-DNA-based biomarkers precisely and promote its wide application for cancer detection, it is very important to unify the source as 
well as the methodologies for cf-DNA extraction and use various internal controls to adjust possible inter-laboratory variations.

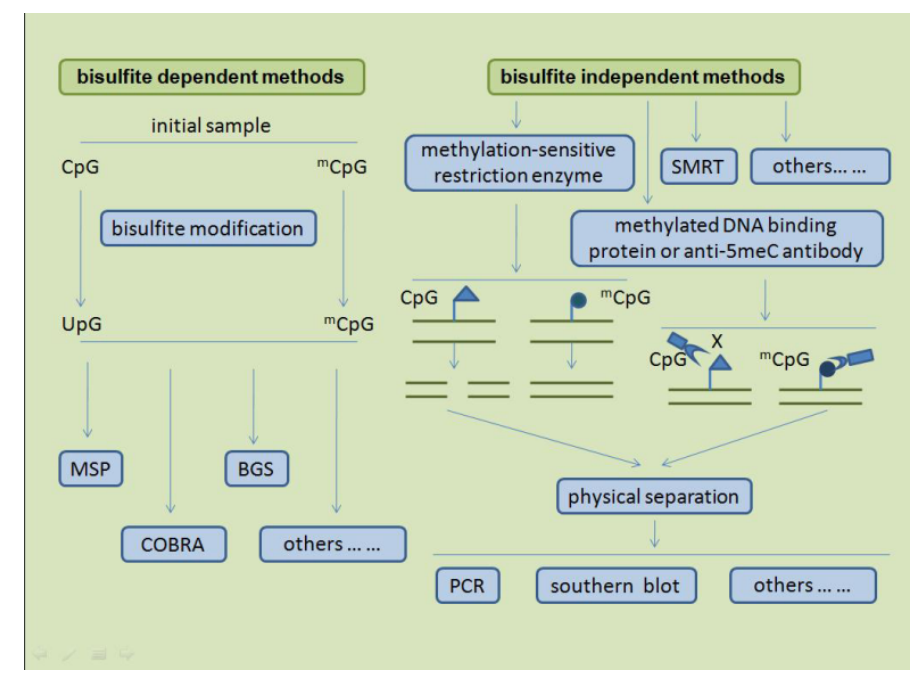

Figure 2. Schematic introductions of various methods for methylation analyses. MSP, BGS and COBRA are based on bisulfite-mediated conversion of unmethylated cytosines into uracils. CpG methylation could block DNA digestion by some restriction enzymes, making it possible to determine methylation status independent of bisulfite treatment by analyzing digestion products. Alternatively, DNA fragments containing methylated CpG sites could be enriched by anti-methylcytosine antibody or methylation binding proteins. Advances in next generation genome sequencing technology led to the development of noel techniques such as SMRT which can specially analyze 5-methylcytosines with genome wide coverage.

In general, the detection of DNA methylation could be bisulfite-dependent or -independent (Figure 2).

The chemical reaction of sodium bisulfite with DNA could convert unmethylated cytosine of CpG into uracil or UpG but leave methylated cytosine of CpG unchanged. The following analyses such as methylation-and unmethylation specific polymerase chain reaction (M- and U-SP), bisulfite genome sequencing (BGS) or combined bisulfite restriction analysis (COBRA) could determine the conversion of $\mathrm{CpG}$ sites of interest, thus reflecting their methylation status as methylated or unmethylated [37]. With varied resolution levels, different bisulfite-dependent DNA methylation analysis methods detect the conversion after bisulfite treatment of genomic DNA, which could have certain artificial effects such as incomplete conversion of unmethylated $\mathrm{CpG}$ into $\mathrm{UpG}$, leading to high rate of false negative conclusion of DNA methylation status.

Recently, some new modifications of cytosine in CpG dinucleotides have been discovered such as 5-hydoxymethylcytosine which was called the sixth base since 5-methylcytosine was named as the fifth base [38]. Generated from the oxidation of 5-methylcytosine by the Tet family of enzymes, 5-hydoxymethylcytosine was first found in bacteriophages and recently 
shown to be abundant in human and mouse brains as well as in embryonic stem cells [39-40]. Although the exact relevance of 5-hydoxymethylcytosine in the genome is still not fully clarified, it has been found to regulate gene expression or promote DNA demethylation. The in vitro synthesized artificial oligonucleotides containing 5-hydoxymethylcytosines can be converted into unmodified cytosines when introduced into mammalian cells, indicating that 5-hydoxymethylcytosine might be one of intermediate products during active DNA demethylation [41]. Therefore, the increase of 5-hydoxymethylcytosine might reflect the demethylation of CPG dinucleotides. Unfortunately, 5-hydoxymethylcytosines, similar to 5-methylcytosines, appear to be resistant to bisulfite-mediated conversion and PCR could amplify DNA fragments containing 5-hydoxymethylcytosines or 5-methylcytosines with similar efficiency [42-43]. Therefore, bisulfite-dependent methylation analyses could produce false positive results by counting 5-hydoxymethylcytosines into 5-methylcytosines. In addition to 5-hydroxymethylcytosines, some forms of DNA modifications such as the seventh base, 5-formylcytosine and the eighth base, 5-carboxylcytosine, have been found in mammalian cells recently [44-47]. As the products of 5-hydoxymethylcytosine oxidation through TET hydroxylases, both 5-formylcytosine and 5-carboxylcytosine will be read as the uracil after bisulfite conversion, thus making it impossible for bisulfite-dependent analyses to distinguish unmodified cytosines from 5-formylcytosines and 5-carboxylcytosines.

Bisulfite independent analyses such as MedIP (methylated DNA immunoprecipitation) could more or less detect DNA methylation specifically. In bisulfite independent analyses, 5methylcytosines are differentiated from unmethylated cytosine by either enzyme digestion or affinity enrichment. DNA methylation analysis using restriction enzyme digestion is based on the property of some methylation-sensitive and -resistant restriction enzymes such as HpaII and MspI that target CCGG for digestion. HpaII fails to cut it once the second cytosine was methylated while MspI-mediated digestion is not affected by DNA methylation, thus making it possible to determine the methylation status of $\mathrm{CpG}$ in the context of CCGG tetranucleotides by analyzing the products of DNAs digested by HpaII and MspI respectively. As a primary method to analyze DNA methylation, it can only determine the methylation of CpG in the context of CCGG tetranucleotides and will overlook the majority of CpG dinucleotides in the genome.

The development of monoclonal antibody specific to 5-methylcytosines revolutionized the analyses of DNA methylation [48-49]. Immunoprecipitated DNA by this antibody could be subject to DNA microarray or even deep sequencing to reveal novel sequences or sites containing 5-methylcytosines [50]. This antibody specifically recognizes 5-methylcytosines but not 5-hydoxymethylcytosines. However, 5-methylcytosines could present not only in CpG dinucleotides but also in CHH or CHG trinucleotides, especially in plants, human embryonic stem cells and probably cancer cells as well. CHH methylation indicates a 5-methylcytosine followed by two nucleotides that may not be guanine and CHG methylation refers to a 5-methylcytosine preceding an adenine, thymine or cytosine base followed by guanine. Such non-CpG DNA methylations were enriched at transposons and repetitive regions, although the exact biological relevance remains unknown. However, antibody against 5-methylcyto- 
sine may precipitate methylated $\mathrm{CHH}$ and $\mathrm{CHG}$ trinucleotide containing DNA fragments in addition to DNA sequences with methylated CpG sites.

DNA methylation functions as the signal for DNA-interacting proteins to maintain genome structure or regulate gene expression. The proteins such as MBD1 (methyl-CpG binding domain protein 1), MeCP2 (methyl CpG binding protein 2) and MBD4 (methyl-CpG binding domain protein 4) bind methylated CpG specifically to regulate gene expression [51-52]. Therefore, methyl-CpG binding domain could specifically enrich differentially methylated regions (DMRs) of physiological relevance [53]. Similar to MeDIP, MBD capture specifically enrich methylated $\mathrm{CpG}$ sites rather than hydroxymethlated $\mathrm{CpG}$ sites. The detailed analysis to compare MeDIP and MBD capture revealed that both enrichment techniques are sensitive enough to identify DMRs in human cancer cells. However, MeDIP enriched more methylated regions with low $\mathrm{CpG}$ densities while $\mathrm{MBD}$ capture favors regions of high $\mathrm{CpG}$ densities and identifies the greater proportion of CpG islands [49].

Recently, the advance of next generation sequencing led to the development of several novel techniques, making it possible to quantitatively analyze DNA methylation at single nucleotide resolution with genome wide coverage. Both the single molecule real time sequencing technology (SMRT) and the single-molecule nanopore DNA sequencing platform could discriminate 5-methylcytosines from other DNA bases including 5-hydroxymethylcytosines even methyladenine independent of bisulfite conversion [54-55]. With many advantages such as less bias during template preparation, lower cost and better accuracy, such new techniques could offer more methods to detect DNA methylation with high specificity and sensitivity in addition to more potential DNA methylation based biomarkers for cancer detection and screening.

\section{Potential DNA methylation biomarkers for cancer detection}

It has been questioned whether the methylated DNA in the circulation is sensitive to detect cancers early enough for curative resection. However, the development of sensitive detection methods confirmed the potential value of DNA methylation in cancer detection (Table 1).

Most of DNA methylation biomarkers are well-known tumor suppressor genes silenced in primary tumor tissues. However, the biomarks do not have to be functional relevant. For example, currently well-used biomarkers such as AFP (Alpha-Fetal Protein), PSA (Prostatespecific antigen) and CEA (Carcinoembryonic antigen) are not tumor suppressor genes with important biological functions. Profiling of methylated DNA in the circulation instead of primary tumor tissues with MeDIP or MBD capture or other methylation specific analyses methods would identify more potential biomarks rather than functional important tumor suppressor genes. 


\begin{tabular}{|c|c|c|c|c|c|}
\hline Cancer & Markers & Sensitivity & Specificity & Methods & Ref. \\
\hline \multirow[t]{3}{*}{ Bladder cancer } & CDKN2A (ARF) CDKN2A & $13 / 27(48 \%)$ & $\mathrm{N} / \mathrm{A}$ & MSP & [58] \\
\hline & (INK4A) & $2 / 27(7 \%)$ & $\mathrm{N} / \mathrm{A}$ & MSP & \\
\hline & CDKN2A (INK4A) & $19 / 86(22 \%)$ & $31 / 31(100 \%)$ & MSP & [59] \\
\hline \multirow[t]{4}{*}{ Breast cancer } & CDKN2A (INK4A) & $5 / 35(14 \%)$ & $\mathrm{N} / \mathrm{A}$ & MS-AP- & {$[56]$} \\
\hline & & & & $P C R$ & \\
\hline & CDKN2A (INK4A) & $6 / 43(14 \%)$ & N/A & MS-AP- & [57] \\
\hline & & & & PCR & \\
\hline \multicolumn{2}{|c|}{ Colorectal cancerMLH1 } & $3 / 18(17 \%)$ & $\mathrm{N} / \mathrm{A}$ & MSP & {$[60]$} \\
\hline & CDKN2A (INK4A) CDKN2A & $14 / 52(27 \%)$ & $44 / 44(100 \%)$ & MSP & [61] \\
\hline & (INK4A) CDKN2A (INK4A) & $13 / 94(11 \%)$ & $\mathrm{N} / \mathrm{A}$ & MSP & [62] \\
\hline & ALX4 & $21 / 58(36 \%)$ & $\mathrm{N} / \mathrm{A}$ & MSP & [63] \\
\hline & $\mathrm{CDH} 4$ & $25 / 30(83 \%)$ & $36 / 52(70 \%)$ & MSP & [64] \\
\hline & NGFR & $32 / 46(70 \%)$ & $17 / 17(100 \%)$ & MSP & [65] \\
\hline & RUNX3 & $68 / 133(51 \%)$ & $150 / 179(84 \%)$ & MSP & [66] \\
\hline & SEPT9 & $11 / 17(65 \%)$ & $10 / 10(100 \%)$ & MSP & [67] \\
\hline & TMEFF2 & $92 / 133(69 \%)$ & $154 / 179(86 \%)$ & MSP & {$[66]$} \\
\hline & & $87 / 133(65 \%)$ & $123 / 179(69 \%)$ & MSP & \\
\hline Esophageal & APC & $13 / 52(25 \%)$ & $54 / 54(100 \%)$ & MSP & [68] \\
\hline \multirow[t]{2}{*}{ cancer } & APC & $2 / 32(6 \%)$ & $54 / 54(100 \%)$ & MSP & \\
\hline & CDKN2A (INK4A) & $7 / 38(18 \%)$ & $\mathrm{N} / \mathrm{A}$ & MSP & [69] \\
\hline \multirow[t]{6}{*}{ Gastric cancer } & $\mathrm{CDH} 1$ & $31 / 54$ (57\%) & $30 / 30(100 \%)$ & MSP & [70] \\
\hline & CDKN2A (INK4A) & $28 / 54(52 \%)$ & $30 / 30(100 \%)$ & MSP & \\
\hline & CDKN2B (INK4B) & $30 / 54(56 \%)$ & $30 / 30(100 \%)$ & MSP & \\
\hline & DAPK1 & $26 / 54(48 \%)$ & $30 / 30(100 \%)$ & MSP & \\
\hline & GSTP1 & 18/54 (15\%) & $30 / 30(100 \%)$ & MSP & \\
\hline & Panel of five & $45 / 54(83 \%)$ & $30 / 30(100 \%)$ & MSP & \\
\hline Head and neck & CDKN2A (INK4A) & $8 / 95(8 \%)$ & $\mathrm{N} / \mathrm{A}$ & MSP & [71] \\
\hline \multirow[t]{4}{*}{ cancer } & DAPK 1 & $3 / 95(3 \%)$ & $\mathrm{N} / \mathrm{A}$ & MSP & \\
\hline & MGMT & 14/95 (15\%) & $\mathrm{N} / \mathrm{A}$ & MSP & \\
\hline & Panel of three & $21 / 95(22 \%)$ & $\mathrm{N} / \mathrm{A}$ & MSP & \\
\hline & DAPK1 & $\mathrm{N} / \mathrm{A}$ & $\mathrm{N} / \mathrm{A}$ & MSP & [72] \\
\hline \multirow[t]{2}{*}{ Liver cancer } & CDKN2A (INK4A) CDKN2B & $13 / 22(45 \%)$ & $48 / 48(100 \%)$ & MSP & [73] \\
\hline & (INK4B) & $4 / 25(16 \%)$ & $35 / 35(100 \%)$ & MSP & [74] \\
\hline \multirow[t]{7}{*}{ Lung cancer } & CDKN2A (INK4A) & $3 / 22(14 \%)$ & $\mathrm{N} / \mathrm{A}$ & MSP & {$[75]$} \\
\hline & DAPK1 & $4 / 22(18 \%)$ & $\mathrm{N} / \mathrm{A}$ & MSP & \\
\hline & GSTP1 & $1 / 22(5 \%)$ & $\mathrm{N} / \mathrm{A}$ & MSP & \\
\hline & MGMT & $4 / 22(18 \%)$ & $\mathrm{N} / \mathrm{A}$ & MSP & \\
\hline & Panel of four & $11 / 22(50 \%)$ & N/A & MSP & \\
\hline & CDKN2A (INK4A) & $\mathrm{N} / \mathrm{A}$ & $\mathrm{N} / \mathrm{A}$ & MSP & [76] \\
\hline & APC & $42 / 89(47 \%)$ & $50 / 50(100 \%)$ & MSP & [77] \\
\hline
\end{tabular}




\begin{tabular}{llllll}
\hline Cancer & Markers & Sensitivity & Specificity & Methods & Ref. \\
\hline & CDKN2A (INK4A) & $77 / 105(73 \%)$ & N/A & MSP & {$[78]$} \\
& CDKN2A (INK4A) & $12 / 35(34 \%)$ & $15 / 15(100 \%)$ & MSP & {$[79]$} \\
\hline Prostate cancer & GSTP1 & $23 / 33(70 \%)$ & $22 / 22(100 \%)$ & MSP & {$[80]$} \\
& GSTP1 & $25 / 69(36 \%)$ & $31 / 31(100 \%)$ & MSP & {$[81]$}
\end{tabular}

Table 1. Methylated DNA biomarkers in the literature.

Most of the methods used for methylation biomarkers analyses are still bisulfite dependent. Few reports used MS-AP-PCR (methylation-sensitive arbitrarily primed PCR) which takes the advantage of methylation sensitive restriction endonucleases to distinguish methylated CpG from unmethylated form, although the sensitivity seems to be lower than MSP [56-57]. Interestingly, combination of more than one methylated DNA as a methylation panel could great increase the sensitivity for cancer detection without significant reduction of specificity. Unfortunately, most of studies were performed in a retrospective manner. More prospective studies with large sample sizes will be warranted to compare different approaches especially bisulfite-independent methods in addition to confirm the value of DNA methylation for cancer detection.

\section{Conclusion and Perspectives}

With the development of the next generation genome sequencing as well as single molecular PCR, it became possible to analyze trace amount of DNAs including circulating cell-free DNA. Circulating tumor cells have been proven its value in prognosis predication even early detection of various cancers. The analyses of methylated DNAs in the circulating will be the next promising epigenetic biomarkers for cancer detection. As one of the intermediate products of DNA demethylation, 5-hydroxymethlcytosines are resistant to bisulfite conversion. Therefore, it should be carefully to interpret the data of methylation analyses based on bisulfite treatment due to potentially high rate of false positive results. Although some methylated DNAs were found to valuable as a single biomarker for cancer detection, more potential DNA methylations will be found after the wide application of SMRT and other sequencing platforms with high speed, depth and accuracy. DNA methylation signatures including a panel of methylated DNAs will show the potential in the early diagnosis or screening and prognosis or therapy response prediction of many cancers. In addition, such DNA methylation biomarkers could be more sensitive and specific for cancer detection when combined with well-used biochemical biomarkers. However, unified methods with gold standards will be warranted to promote the development and clinical application of DNA methylation biomarkers. 


\section{Acknowledgements}

This work was supported by the National Natural Science Foundation of China (81071963; 81071652), Program for Innovative Research Team in Science and technology of Zhejiang Province (2010R50046) and Program for Qianjiang Scholarship in Zhejiang Province (2011R10061; 2011R10073).

\section{Author details}

Hongchuan Jin, Yanning Ma, Qi Shen and Xian Wang*

*Address all correspondence to: wangx118@yahoo.com

Department of Medical Oncology, Laboratory of Cancer Epigenetics, Biomedical Research Center, Sir Runrun Shaw Hospital, Zhejiang University, China

\section{References}

[1] Jones, P. A., \& Baylin, S. B. (2007). The epigenomics of cancer. Cell, 128, 683-692.

[2] Jones, P. A., \& Baylin, S. B. (2002). The fundamental role of epigenetic events in cancer. Nat Rev Genet, 3, 415-428.

[3] Baylin, S. B., Esteller, M., Rountree, M. R., Bachman, K. E., Schuebel, K., \& Herman, J. G. (2001). Aberrant patterns of DNA methylation, chromatin formation and gene expression in cancer. Hum Mol Genet, 10, 687-692.

[4] Baylin, S. B., \& Herman, J. G. (2000). DNA hypermethylation in tumorigenesis: epigenetics joins genetics. Trends Genet, 16, 168-174.

[5] Oki, Y., \& Issa, J. P. (2006). Review: recent clinical trials in epigenetic therapy. Rev Recent Clin Trials, 1, 169-182.

[6] Kelly, T. K., De Carvalho, D. D., \& Jones, P. A. (2010). Epigenetic modifications as therapeutic targets. Nat Biotechnol, 28, 1069-1078.

[7] Ramalingam, S. S., Maitland, M. L., Frankel, P., Argiris, A. E., Koczywas, M., Gitlitz, B., Thomas, S., Espinoza-Delgado, I., Vokes, E. E, Gandara, D. R., \& Belani, C. P. (2010). Carboplatin and Paclitaxel in combination with either vorinostat or placebo for first-line therapy of advanced non-small-cell lung cancer. J Clin Oncol, 28, 56-62.

[8] Braiteh, F., Soriano, A. O., Garcia-Manero, G., Hong, D., Johnson, MM, Silva Lde, P., Yang, H., Alexander, S., Wolff, J., \& Kurzrock, R. (2008). Phase I study of epigenetic modulation with 5-azacytidine and valproic acid in patients with advanced cancers. Clin Cancer Res, 14, 6296-6301. 
[9] Font, P. (2011). Azacitidine for the treatment of patients with acute myeloid leukemia with 20\%-30\% blasts and multilineage dysplasia. Adv Ther, 3(28), 1-9.

[10] Fu, S., Hu, W., Iyer, R., Kavanagh, J. J., Coleman, R. L., Levenback, C. F., Sood, A. K., Wolf, J. K., Gershenson, D. M., Markman, M., Hennessy, B. T., Kurzrock, R., \& Bast, R. C., Jr. (2011). Phase 1b-2a study to reverse platinum resistance through use of a hypomethylating agent, azacitidine, in patients with platinum-resistant or platinumrefractory epithelial ovarian cancer. Cancer, 117, 1661-1669.

[11] Silverman, L. R., Fenaux, P., Mufti, G. J., Santini, V., Hellstrom-Lindberg, E., Gattermann, N., Sanz, G., List, A. F., Gore, S. D., \& Seymour, J. F. (2011). Continued azacitidine therapy beyond time of first response improves quality of response in patients with higher-risk myelodysplastic syndromes. Cancer.

[12] Sonpavde, G., Aparicio, A. M., Zhan, F., North, B., Delaune, R., Garbo, L. E., Rousey, S. R., Weinstein, R. E., Xiao, L., Boehm, K. A., Asmar, L., Fleming, M. T., Galsky, M. D., Berry, W. R., \& Von Hoff, D. D. (2011). Azacitidine favorably modulates PSA kinetics correlating with plasma DNA LINE-1 hypomethylation in men with chemonaive castration-resistant prostate cancer. Urol Oncol, 29, 682-689.

[13] Keating, G. M. (2012). Azacitidine: a review of its use in the management of myelodysplastic syndromes/acute myeloid leukaemia. Drugs, 72, 1111-1136.

[14] Alix-Panabieres, C., Schwarzenbach, H., \& Pantel, K. (2012). Circulating tumor cells and circulating tumor DNA. Annu Rev Med, 63, 199-215.

[15] Zhe, X., Cher, M. L., \& Bonfil, R. D. (2011). Circulating tumor cells: finding the needle in the haystack. Am J Cancer Res, 1, 740-751.

[16] Fidler, I. J. (2003). The pathogenesis of cancer metastasis: the 'seed and soil' hypothesis revisited. Nat Rev Cancer, 3, 453-458.

[17] Ghossein, RA, Bhattacharya, S, \& Rosai, J. (1999). Molecular detection of micrometastases and circulating tumor cells in solid tumors. Clin Cancer Res, 5, 1950-1960.

[18] Pelkey, TJ, Frierson, H. F., Jr, \& Bruns, D. E. (1996). Molecular and immunological detection of circulating tumor cells and micrometastases from solid tumors. Clin Chem, $42,1369-1381$.

[19] Mocellin, S., Keilholz, U., Rossi, C. R., \& Nitti, D. (2006). Circulating tumor cells: the ‘leukemic phase' of solid cancers. Trends Mol Med, 12, 130-139.

[20] Chimonidou, M., Strati, A., Tzitzira, A., Sotiropoulou, G., Malamos, N., Georgoulias, V., \& Lianidou, E. S. (2011). DNA methylation of tumor suppressor and metastasis suppressor genes in circulating tumor cells. Clin Chem, 57, 1169-1177.

[21] Garcia-Olmo, D. C., Gutierrez-Gonzalez, L., Ruiz-Piqueras, R., Picazo, M. G., \& Garcia-Olmo, D. (2005). Detection of circulating tumor cells and of tumor DNA in plasma during tumor progression in rats. Cancer Lett, 217, 115-123. 
[22] Matuschek, C., Bolke, E., Lammering, G., Gerber, P. A., Peiper, M., Budach, W., Taskin, H., Prisack, H. B., Schieren, G., Orth, K., \& Bojar, H. (2010). Methylated APC and GSTP1 Genes in Serum DNA Correlate with the Presence of Circulating Blood Tumor Cells and are Associated with a More Aggressive and Advanced Breast Cancer Disease. Eur J Med Res, 15, 277-286.

[23] Kohler, C., Barekati, Z., Radpour, R., \& Zhong, X. Y. (2011). Cell-free DNA in the circulation as a potential cancer biomarker. Anticancer Res, 31, 2623-2628.

[24] Mittra, I., Nair, N. K., \& Mishra, P. K. (2012). Nucleic acids in circulation: Are they harmful to the host? J Biosci, 37, 301-312.

[25] Hung, EC, Chiu, RW, \& Lo, YM. (2009). Detection of circulating fetal nucleic acids: a review of methods and applications. J Clin Pathol, 62, 308-313.

[26] Stroun, M., \& Anker, P. (2005). Circulating DNA in higher organisms cancer detection brings back to life an ignored phenomenon. Cell Mol Biol (Noisy-le-grand), 51, 767-774.

[27] Koffler, D., Agnello, V., Winchester, R., \& Kunkel, H. G. (1973). The occurrence of single-stranded DNA in the serum of patients with systemic lupus erythematosus and other diseases. J Clin Invest, 52, 198-204.

[28] Leon, S. A., Ehrlich, G. E., Shapiro, B., \& Labbate, V. A. (1977). Free DNA in the serum of rheumatoid arthritis patients. J Rheumatol, 4, 139-143.

[29] Leon, S. A., Shapiro, B., Sklaroff, D. M., \& Yaros, M. J. (1977). Free DNA in the serum of cancer patients and the effect of therapy. Cancer Res, 37, 646-650.

[30] Lo, Y. M. (2001). Circulating nucleic acids in plasma and serum: an overview. Ann N Y Acad Sci, 945, 1-7.

[31] Anker, P., Lyautey, J., Lederrey, C., \& Stroun, M. (2001). Circulating nucleic acids in plasma or serum. Clin Chim Acta ., 313, 143-146.

[32] Yamada, T., Nakamori, S., Ohzato, H., Oshima, S., Aoki, T., Higaki, N., Sugimoto, K., Akagi, K., Fujiwara, Y., Nishisho, I., Sakon, M., Gotoh, M., \& Monden, M. (1998). Detection of K-ras gene mutations in plasma DNA of patients with pancreatic adenocarcinoma: correlation with clinicopathological features. Clin Cancer Res, 4, 1527-1532.

[33] Castells, A., Puig, P., Mora, J., Boadas, J., Boix, L., Urgell, E., Sole, M., Capella, G., Lluis, F., Fernandez-Cruz, L., Navarro, S., \& Farre, A. (1999 ). Kras mutations in DNA extracted from the plasma of patients with pancreatic carcinoma: diagnostic utility and prognostic significance. J Clin Oncol, 17, 578-584.

[34] Lui, Y. Y., Woo, K. S., Wang, A. Y., Yeung, C. K., Li, P. K., Chau, E., Ruygrok, P., \& Lo, Y. M. (2003). Origin of plasma cell-free DNA after solid organ transplantation. Clin Chem, 49, 495-496. 
[35] Chan, K. C., Yeung, S. W., Lui, W. B., Rainer, T. H., \& Lo, Y. M. (2005). Effects of preanalytical factors on the molecular size of cell-free DNA in blood. Clin Chem, 51, 781-784.

[36] Board, R. E., Knight, L., Greystoke, A., Blackhall, F. H., Hughes, A., Dive, C., \& Ranson, M. (2008). DNA methylation in circulating tumour DNA as a biomarker for cancer. Biomark Insights, 2, 307-319.

[37] Herman, J. G., Graff, J. R., Myohanen, S., Nelkin, B. D., \& Baylin, S. B. (1996). Methylation-specific PCR: a novel PCR assay for methylation status of CpG islands. Proc Natl Acad Sci U S A, 93, 9821-9826.

[38] Branco, M. R., Ficz, G., \& Reik, W. (2012). Uncovering the role of 5-hydroxymethylcytosine in the epigenome. Nat Rev Genet, 13, 7-13.

[39] Tahiliani, M., Koh, K. P., Shen, Y., Pastor, W. A., Bandukwala, H., Brudno, Y., Agarwal, S., Iyer, L. M., Liu, D. R., Aravind, L., \& Rao, A. (2009). Conversion of 5-methylcytosine to 5-hydroxymethylcytosine in mammalian DNA by MLL partner TET1. Science, 324, 930-935.

[40] Wyatt, G. R., \& Cohen, SS. (1952). A new pyrimidine base from bacteriophage nucleic acids. Nature, 170, 1072-1073.

[41] Guo, J. U., Su, Y., Zhong, C., Ming, G. L., \& Song, H. (2011). Hydroxylation of 5methylcytosine by TET1 promotes active DNA demethylation in the adult brain. Cell, $145,423-434$.

[42] Nestor, C., Ruzov, A., Meehan, R., \& Dunican, D. (2010). Enzymatic approaches and bisulfite sequencing cannot distinguish between 5-methylcytosine and 5-hydroxymethylcytosine in DNA. Biotechniques, 48, 317-319.

[43] Huang, Y., Pastor, W. A., Shen, Y., Tahiliani, M., Liu, D. R., \& Rao, A. (2010). The behaviour of 5-hydroxymethylcytosine in bisulfite sequencing. PLoS One, 5, e8888.

[44] Pfaffeneder, T., Hackner, B., Truss, M., Munzel, M., Muller, M., Deiml, C. A., Hagemeier, C., \& Carell, T. (2011). The discovery of 5-formylcytosine in embryonic stem cell DNA. Angew Chem Int Ed Engl, 50, 7008-7012.

[45] Zhang, L., Lu, X., Lu, J., Liang, H., Dai, Q., Xu, G. L., Luo, C., Jiang, H., \& He, C. (2012). Thymine DNA glycosylase specifically recognizes 5-carboxylcytosine-modified DNA. Nat Chem Biol, 8, 328-330.

[46] Maiti, A., \& Drohat, A. C. (2011). Thymine DNA glycosylase can rapidly excise 5-formylcytosine and 5-carboxylcytosine: potential implications for active demethylation of CpG sites. J Biol Chem, 286, 35334-35338.

[47] Ito, S., Shen, L., Dai, Q., Wu, S. C., Collins, L. B., Swenberg, J. A., He, C., \& Zhang, Y. (2011). Tet proteins can convert 5-methylcytosine to 5-formylcytosine and 5-carboxylcytosine. Science, 333, 1300-1303. 
[48] Jacinto, F. V., Ballestar, E., \& Esteller, M. (2008). Methyl-DNA immunoprecipitation (MeDIP): hunting down the DNA methylome. Biotechniques, 44, 35, 37,39passim.

[49] Nair, S. S., Coolen, M. W., Stirzaker, C., Song, J. Z., Statham, A. L., Strbenac, D., Robinson, M. D., \& Clark, S. J. (2011). Comparison of methyl-DNA immunoprecipitation (MeDIP) and methyl-CpG binding domain (MBD) protein capture for genome-wide DNA methylation analysis reveal CpG sequence coverage bias. Epigenetics, 6, 34-44.

[50] Gupta, R., Nagarajan, A., \& Wajapeyee, N. (2010). Advances in genome-wide DNA methylation analysis. Biotechniques, 49, 3-11.

[51] Bogdanovic, O., \& Veenstra, G. J. (2009). DNA methylation and methyl-CpG binding proteins: developmental requirements and function. Chromosoma, 118, 549-565.

[52] Ballestar, E., \& Esteller, M. (2005). Methyl-CpG-binding proteins in cancer: blaming the DNA methylation messenger. Biochem Cell Biol, 83, 374-384.

[53] Fraga, M. F., Ballestar, E., Montoya, G., Taysavang, P., Wade, P. A., \& Esteller, M. (2003). The affinity of different MBD proteins for a specific methylated locus depends on their intrinsic binding properties. Nucleic Acids Res, 31, 1765-1774.

[54] Flusberg, BA, Webster, D. R., Lee, J. H., Travers, K. J., Olivares, E. C., Clark, T. A., Korlach, J., \& Turner, S. W. (2010). Direct detection of DNA methylation during single-molecule, real-time sequencing. Nat Methods, 7, 461-465.

[55] Clarke, J., Wu, H. C., Jayasinghe, L., Patel, A., Reid, S., \& Bayley, H. (2009). Continuous base identification for single-molecule nanopore DNA sequencing. Nat Nanotechnol, 4, 265-270.

[56] Silva, J. M., Dominguez, G., Villanueva, Gonzalez. R., Garcia, J. M., Corbacho, C., Provencio, M., Espana, P., \& Bonilla, F. (1999). Aberrant DNA methylation of the p16INK4a gene in plasma DNA of breast cancer patients. Br J Cancer, 80, 1262-1264.

[57] Silva, J. M., Dominguez, G., Garcia, J. M., Gonzalez, R., Villanueva, M. J., Navarro, F., Provencio, M., San Martin, S., Espana, P., \& Bonilla, F. (1999). Presence of tumor DNA in plasma of breast cancer patients: clinicopathological correlations. Cancer Res, $59,3251-3256$.

[58] Domínguez, G., Carballido, J., Silva, J., Silva, J. M., García, J. M., Menéndez, J., Provencio, M., España, P., \& Bonilla, F. (2002). p14ARF Promoter Hypermethylation in Plasma DNA as an Indicator of Disease Recurrence in Bladder Cancer Patients. Clinical Cancer Research, 8, 980-985.

[59] Valenzuela, M. T., Galisteo, R., Zuluaga, A., Villalobos, M., Núñez, M. I., Oliver, F. J., \& Ruiz de, Almodóvar. J. M. (2002). Assessing the Use of p16INK4a Promoter Gene Methylation in Serum for Detection of Bladder Cancer. European Urology, 42, 622-630.

[60] Grady, W. M., Rajput, A., Lutterbaugh, J. D., \& Markowitz, S. D. (2001). Detection of aberrantly methylated hMLH1 promoter DNA in the serum of patients with microsatellite unstable colon cancer. Cancer Res, 61, 900-902. 
[61] Zou, H. Z., Yu, B. M., Wang, Z. W., Sun, J. Y., Cang, H., Gao, F., Li, D. H., Zhao, R., Feng, G. G., \& Yi, J. (2002). Detection of aberrant 16-methylation in the serum of colorectal cancer patients. Clinical Cancer Research, 8, 188-191.

[62] Nakayama, H., Hibi, K., Taguchi, M., Takase, T., Yamazaki, T., Kasai, Y., Ito, K., Akiyama, S., \& Nakao, A. (2002). Molecular detection of p16 promoter methylation in the serum of colorectal cancer patients. Cancer letters, 188, 115-119.

[63] Lecomte, T., Berger, A., Zinzindohoué, F., Micard, S., Landi, B., Blons, H., Beaune, P., Cugnenc, P. H., \& Laurent-Puig, P. (2002). Detection of free-circulating tumor-associated DNA in plasma of colorectal cancer patients and its association with prognosis. International journal of cancer, 100, 542-548.

[64] Ebert, M., Model, F., Mooney, S., Hale, K., Lograsso, J., Tonnes-Priddy, L., Hoffmann, J., Csepregi, A., Röcken, C., \& Molnar, B. (2006). Aristaless-like Homeobox-4 Gene Methylation Is a Potential Marker for Colorectal Adenocarcinomas. Gastroenterology, $131,1418-1430$.

[65] Miotto, E., Sabbioni, S., Veronese, A., Calin, G. A., Gullini, S., Liboni, A., Gramantieri, L., Bolondi, L., Ferrazzi, E., \& Gafà, R. (2004). Frequent aberrant methylation of the $\mathrm{CDH} 4$ gene promoter in human colorectal and gastric cancer. Cancer research, 64, 8156.

[66] Lofton-Day, C., Model, F., De Vos, T., Tetzner, R., Distler, J., Schuster, M., Song, X., Lesche, R., Liebenberg, V., \& Ebert, M. (2008). DNA methylation biomarkers for blood-based colorectal cancer screening. Clinical chemistry, 54, 414-423.

[67] Tan, S. H., Ida, H., Lau, Q. C., Goh, B. C., Chieng, W. S., Loh, M., \& Ito, Y. (2007). Detection of promoter hypermethylation in serum samples of cancer patients by methylation-specific polymerase chain reaction for tumour suppressor genes including RUNX3. Oncology reports, 18, 1225-1230.

[68] Kawakami, K, Brabender, J, Lord, RV, Groshen, S, Greenwald, BD, Krasna, MJ, Yin, J, Fleisher, AS, Abraham, J. M., \& Beer, D. G. (2000). Hypermethylated APC DNA in plasma and prognosis of patients with esophageal adenocarcinoma. Journal of the $\mathrm{Na}$ tional Cancer Institute, 92, 1805-1811.

[69] Hibi, K., Taguchi, M., Nakayama, H., Takase, T., Kasai, Y., Ito, K., Akiyama, S., \& Nakao, A. (2001). Molecular detection of p16 promoter methylation in the serum of patients with esophageal squamous cell carcinoma. Clinical Cancer Research, 7, 3135-3138.

[70] Lee, T. L., Leung, W. K., Chan, M. W. Y., Ng, E. K. W., Tong, J. H. M., Lo., K. W., Chung, S. C. S., Sung, J. J. Y., \& To, K. F. (2002). Detection of gene promoter hypermethylation in the tumor and serum of patients with gastric carcinoma. Clinical Cancer Research, 8, 1761-1766. 
[71] Sanchez-Cespedes, M., Esteller, M., Wu, L., Nawroz-Danish, H., Yoo, G. H., Koch, W. M., Jen, J., Herman, J. G., \& Sidransky, D. (2000). Gene promoter hypermethylation in tumors and serum of head and neck cancer patients. Cancer research, 60, 892.

[72] Wong, T. S., Chang, H. W., Tang, K. C., Wei, W. I., Kwong, D. L. W., Jen, J., Sham, J. S. T., Yuen, A. P. W., \& Kwong, Y. L. (2002). High frequency of promoter hypermethylation of the death-associated protein-kinase gene in nasopharyngeal carcinoma and its detection in the peripheral blood of patients. Clinical Cancer Research, 8, 433-437.

[73] Wong, I. H. N., Dennis, Lo. Y., Zhang, J., Liew, C. T., Ng, M. H. L., Wong, N., Lai, P., Lau, W. Y., Hjelm, N. M., \& Johnson, P. J. (1999). Detection of aberrant p16methylation in the plasma and serum of liver cancer patients. Cancer research, 59, 71.

[74] Wong, I. H. N., Lo, Y. M. D., Yeo, W., Lau, W. Y., \& Johnson, P. J. (2000). Frequent p15 promoter methylation in tumor and peripheral blood from hepatocellular carcinoma patients. Clinical Cancer Research, 6, 3516-3521.

[75] Esteller, M., Sanchez-Cespedes, M., Rosell, R., Sidransky, D., Baylin, S. B., \& Herman, J. G. (1999). Detection of aberrant promoter hypermethylation of tumor suppressor genes in serum DNA from non-small cell lung cancer patients. Cancer research, 59, 67.

[76] Kurakawa, E., Shimamoto, T., Utsumi, K., Hirano, T., Kato, H., \& Ohyashiki, K. (2001). Hypermethylation of p16INK4 a) and p15 (INK4b) genes in non-small cell lung cancer. International journal of oncology, 19, 277.

[77] Usadel, H., Brabender, J., Danenberg, K. D., Jerónimo, C., Harden, S., Engles, J., Danenberg, P. V., Yang, S., \& Sidransky, D. (2002). Quantitative adenomatous polyposis coli promoter methylation analysis in tumor tissue, serum, and plasma DNA of patients with lung cancer. Cancer research, 62, 371-375.

[78] An, Q., Liu, Y., Gao, Y., Huang, J., Fong, X., Li, L., Zhang, D., \& Cheng, S. (2002). Detection of p16 hypermethylation in circulating plasma DNA of non-small cell lung cancer patients. Cancer letters, 188, 109-114.

[79] Bearzatto, A., Conte, D., Frattini, M., Zaffaroni, N., Andriani, F., Balestra, D., Tavecchio, L., Daidone, M. G., \& Sozzi, G. (2002). p16INK4ahypermethylation detected by fluorescent methylation-specific PCR in plasmas from non-small cell lung cancer. Clinical Cancer Research, 8, 3782-3787.

[80] Goessl, C., Krause, H., Müller, M., Heicappell, R., Schrader, M., Sachsinger, J., \& Miller, K. (2000). Fluorescent methylation-specific polymerase chain reaction for DNAbased detection of prostate cancer in bodily fluids. Cancer research, 60, 5941-5945.

[81] Jeronimo, C., Usadel, H., Henrique, R., Silva, C., Oliveira, J., Lopes, C., \& Sidransky, D. (2002). Quantitative GSTP1 hypermethylation in bodily fluids of patients with prostate cancer. Urology, 60, 1131-1135. 